\title{
Upper extremity arterial thromboembolism in a patient with severe COVID-19 pneumonia: A case report
}

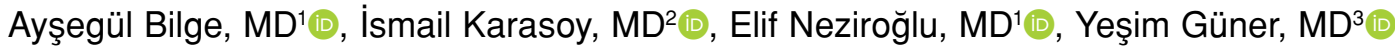 \\ ${ }^{1}$ Department of Anesthesiology and Reanimation, Gümüşhane State Hospital, Gümüşhane, Turkey \\ ${ }^{2}$ Department of Orthopedics and Traumatology, Gümüşhane State Hospital, Gümüşhane, Turkey \\ ${ }^{3}$ Department of Cardiovascular Surgery, Gümüşhane State Hospital, Gümüşhane, Turkey
}

Novel coronavirus disease (COVID-19) is an infectious disease caused by severe acute respiratory syndrome coronavirus-2 (SARS-CoV-2) that often affects the upper respiratory tract. ${ }^{[1]}$ It was declared as pandemic by the World Health Organization (WHO) on March 11 1 th 2020 . As of January 2021, nearly 100 million cases and more than 2 million deaths have been reported. ${ }^{[2]}$

Although COVID-19 primarily affects the respiratory system, it can affect multiple organ systems in certain cases, leading to serious complications, such as acute respiratory distress syndrome (ARDS) and multiple organ failure. ${ }^{[3]}$ Nearly 20 to $55 \%$ of patients with COVID-19 experience coagulation disorders that cause high mortality in line with the severity of the clinical picture. ${ }^{[4]}$ Mortality in patients with thrombotic events requiring intensive care is 5.4 times higher than that in such patients without

Received: March 02, 2021

Accepted: March 25, 2021

Published online: June 11, 2021

Correspondence: İsmail Karasoy, MD. Gümüşhane Devlet Hastanesi Ortopedi ve Travmatoloji Kliniği, 29000 Gümüşhane, Türkiye.

E-mail: ismail.karasoy@gmail.com

Doi: $10.52312 / j d r s .2021 .82766$

Citation: Bilge A, Karasoy I, Neziroğlu E, Güner Y. Upper extremity arterial thromboembolism in a patient with severe COVID-19 pneumonia: A case report. Jt Dis Relat Surg 2021;32(2):551-555.

(2021 All right reserved by the Turkish Joint Diseases Foundation

This is an open access article under the terms of the Creative Commons Attribution-NonCommercial License, which permits use, distribution and reproduction in any medium, provided the original work is properly cited and is not used for commercial purposes (http://creativecommons.org/licenses/by-nc/4.0/).

\section{ABSTRACT}

Although novel coronavirus-2019 (COVID-19) primarily affects the respiratory system, it can affect multiple organ systems, leading to serious complications, such as acute respiratory distress syndrome (ARDS) and multiple organ failure. Nearly 20 to $55 \%$ of patients with COVID-19 experience coagulation disorders that cause high mortality in line with the severity of the clinical picture. Thromboembolism can be observed in both venous and arterial systems. The vast majority of thromboembolic events are associated with the venous system and are often observed as pulmonary embolism. Arterial thromboembolisms often involve the arteries in the lower extremities, followed by those in the upper extremities. Herein, we report a rare case of COVID-19 pneumonia whose left arm was amputated at the forearm level after arterial thromboembolism in the left upper extremity. This case report is valuable, as it is the first reported case of upper extremity arterial thromboembolism in Turkey, as well as the only case in the literature in which the patient underwent four surgical interventions and is still alive.

Keywords: Amputation, arterial thromboembolism, coagulopathy, COVID-19, upper extremity.

this condition. ${ }^{[5]}$ Thromboembolism can be observed in both venous and arterial systems. The vast majority of thromboembolic events are associated with the venous system and are often observed as pulmonary embolism. ${ }^{[6]}$ Arterial thromboembolisms often involve the arteries in the lower extremities, followed by those in the upper extremities. ${ }^{[7]}$

Herein, we report a rare case of COVID-19 pneumonia whose left arm was amputated at the forearm level after arterial thromboembolism in the left upper extremity, despite receiving anticoagulant treatment in the intensive care unit (ICU), and was discharged with recovery after treatment. This case report is valuable, as it is the first reported case of upper extremity arterial thromboembolism in Turkey, as well as the only case in the literature in which the 
patient underwent four surgical interventions and is still alive. ${ }^{[8]}$

\section{CASE REPORT}

A 73-year-old male patient with poor general condition presented to the emergency department on November $13^{\text {th }}, 2020$ with the complaint of dyspnea. The patient had no history of additional diseases other than hypertension and benign prostatic hyperplasia (BPH); however, he received no permanent antihypertensive treatment. The patient was evaluated with a preliminary diagnosis of COVID-19 pneumonia and underwent thoracic computed tomography (CT) in the emergency department. Multiple bilateral ground-glass opacities and areas of consolidation were observed on CT images. The clinical condition of the patient was compatible with that of severe ARDS (Figure 1). Although the patient was given oxygen with a Venturi mask at $16 \mathrm{~L} / \mathrm{min}$ in the emergency department, oxygen saturation was $<85 \%$, and the patient was shifted to the ICU with the diagnosis of COVID-19 pneumonia. Based on laboratory parameters of the patient assessed during hospitalization in ICU, activated partial thromboplastin time (aPTT) and international normalized ratio (INR) increased. In addition, D-dimer and ferritin levels were above normal. The platelet count was within normal limit (Table I). During the ICU follow-up, high-flow oxygen and intermittent non-invasive ventilation-continuous positive airway pressure (NIV-CPAP) therapy was initiated with a Venturi mask. On Day 5 of hospitalization, the patient had severe pain in the left arm and, on physical examination, the extremity was found to be cold with the development of cyanosis in the distal part, particularly in the fingers. Nevertheless, brachial and radial pulses could not be detected. The patient underwent consultation at
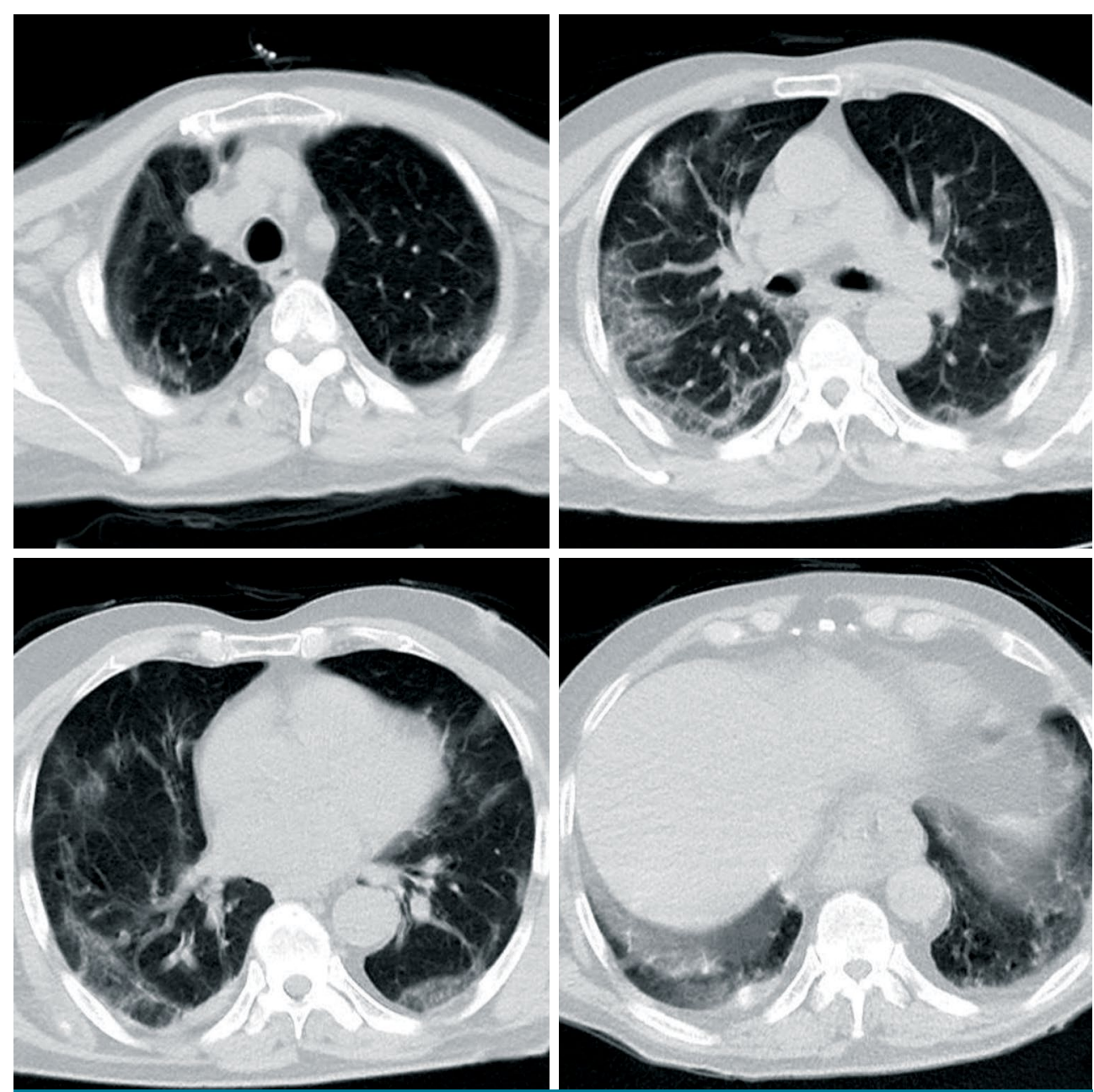

FIGURE 1. Computed tomography images of the lungs taken at emergency room from apex to base. 


\begin{tabular}{|lcc|}
\hline \multicolumn{3}{c|}{$\begin{array}{c}\text { TABLE I } \\
\text { Preoperative laboratory findings }\end{array}$} \\
\hline Test & Result & Reference \\
\hline INR & 1.68 & $0.8-1.5$ \\
aPTT & 79.9 & $20-40$ \\
D-Dimer, $\mu \mathrm{g} / \mathrm{mL}$ & 0.93 & $0-0.5$ \\
Ferritin, $\mathrm{ng} / \mathrm{mL}$ & $>2000$ & $22-322$ \\
Platelets, $\mathrm{K} / \mathrm{mm}^{3}$ & 131.0 & $130-424$ \\
\hline INR: International normalized ratio; aPTT: Activated partial thromboplastin time. \\
\hline
\end{tabular}

cardiovascular surgery clinic to evaluate the possible vascular pathology. The CT-angiography showed the lack of blood flow in the distal end of the left brachial artery (Figure 2). The cardiovascular surgery clinic planned emergency revascularization for the patient.

An incision was made in the left antecubital region under the infraclavicular block. After the radial and ulnar arteries were explored, arteriotomy was performed. Distal and proximal thrombectomy was performed using a 3-Fr Fogarty ${ }^{\circledR}$ catheter. An abundant organized thrombus material was removed. The upper extremities were palpated to detect distal pulses, and cyanosis in the hand began to decrease. Heparin infusion was started, and the patient was transferred to the ICU. Cyanosis in the hand increased again

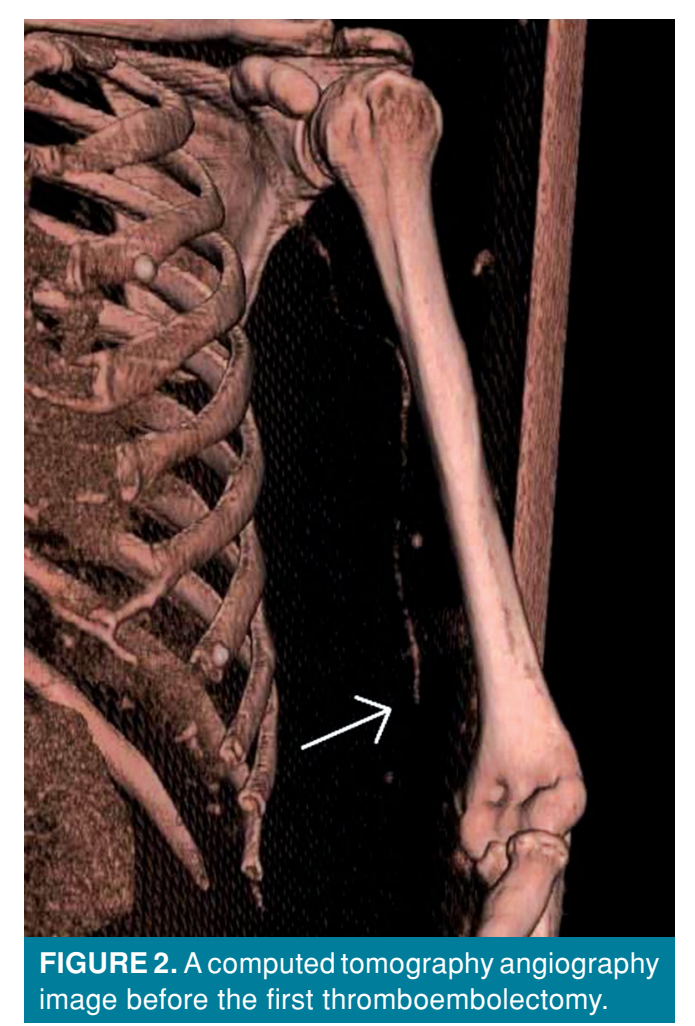

$12 \mathrm{~h}$ after the operation, and repeated thrombectomy was planned for the patient. The thrombus material developing in the radial and ulnar arteries was cleaned with a 3-Fr Fogarty ${ }^{\circledR}$ catheter by entering from the previous incision under the left infraclavicular block. The upper extremities were palpated to detect distal pulses, and the patient was transferred to the ICU. Heparin infusion was administered for one week with follow-up measurement of INR. Afterward, warfarin and low-molecular-weight heparin (LMWH) were simultaneously initiated. Despite all medical and surgical treatments, ischemia persisted in the distal part of the extremity, and a demarcation line started to form (Figure 3). With the recommendations of the cardiovascular surgery clinic, amputation was decided as the treatment course, and the orthopedics and traumatology clinic was consulted for amputation.

On Day $13^{\text {th }}$ after the second thrombectomy, the left arm of the patient was amputated under the left infraclavicular block at the level of the distal forearm. On Day 6 after amputation, the patient was discharged from the ICU and transferred to the pandemic ward, since the patient did not require NIV-CPAP therapy. Oxygen saturation was $90 \%$ (after administration of oxygen treatment at 2 to $3 \mathrm{~L} / \mathrm{min}$ with nasal cannulation), and arterial blood gas levels were within normal limits.

During follow-up in the pandemic ward, the patient underwent consultation with an orthopedic and traumatology specialist due to necrosis at the
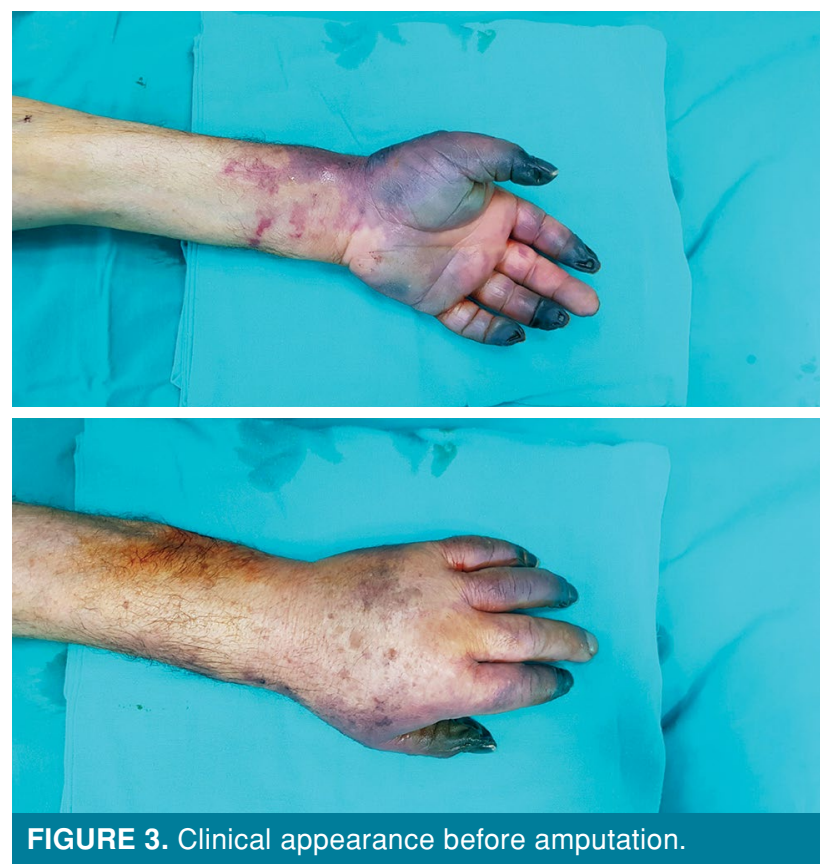

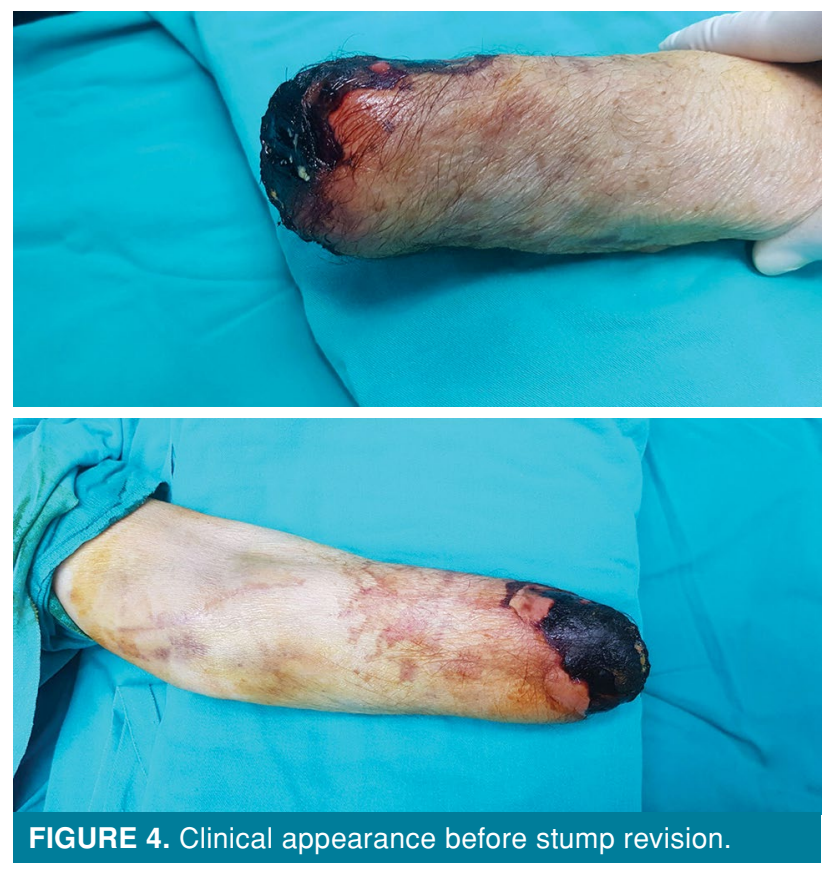

wound site. Stump revision was planned for the patient (Figure 4). After receiving a negative polymerase chain reaction result for COVID-19 and completing COVID-19 treatment, the patient was transferred to the orthopedics and traumatology clinic. Stump revision was performed under infraclavicular block 22 days after the first amputation, and the amputation level was raised to the proximal forearm level. The patient whose wound site was clean during the ward follow-up was discharged with recovery on Day 10 after surgery. No complications were observed during follow-up in the postoperative three weeks.

A written informed consent was obtained from the patient for all diagnostic and therapeutic procedures. The patient and his family were informed that data from the case would be submitted for publication and gave their consent.

\section{DISCUSSION}

It has been demonstrated that COVID-19 affects almost every organ system and causes significant morbidity and mortality. Currently, there is a growing number of evidence in the literature that severe COVID-19 infection causes hypercoagulability that is unlike other infection-related coagulopathies. ${ }^{[4,9]}$ Hypercoagulability may cause pulmonary and deep vein thrombosis, as well as peripheral artery thromboembolism in critically ill patients, despite antic agulant therapy. ${ }^{[10]} \mathrm{A}$ significant elevation of D-dimer and fibrinogen levels with prolonged prothrombin time and aPTT times is frequently reported as hemostatic abnormalities in patients with COVID-19 and have been associated with poor survival rates. ${ }^{[1]}$

Autopsy studies of patients who died from COVID-19 have shown the presence of generalized thrombotic microangiopathy that predominantly affects older males with cardiovascular

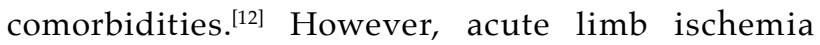
has been also reported in young patients without comorbidities and in those receiving prophylactic LMWH therapy. ${ }^{[13]}$

Klok et al. ${ }^{[5]}$ reported thromboembolic complications $(27 \%$ venous thromboembolism and $3.7 \%$ arterial thromboembolism) at a rate of $31 \%$ in their study in which they examined 184 patients who were treated in the ICU due to COVID-19. Although they reported that $70 \%$ of this patient group had coagulopathy, this condition was found to be an independent predictor for thromboembolic complications.

Although arterial thromboembolism is not a common condition in other infection-related coagulopathies, it is more common in patients with COVID-19 due to the direct endothelial damage caused by SARS-CoV-2 and indirect effect of systemic inflammation. ${ }^{[14]}$ The increased production of the cytokines interleukin (IL)-1, IL-2, IL-6, and tumor necrosis factor-alpha after systemic inflammation activates thrombosis by causing platelet, endothelial, and neutrophil activation..$^{[15,16]}$

Etkin et al. ${ }^{[7]}$ reported limb loss rate and overall mortality rates of $18 \%$ and $46 \%$ in their study including 46 patients with acute arterial ischemia. Among these patients, lower extremity (71\%), upper extremity (12\%), cerebral (10\%), and mesenteric (4\%) involvement were noted. In addition, simultaneous venous thromboembolism $(16 \%)$ was detected in this patient group. A total of $83 \%$ of these patients had D-dimer levels above $1,000 \mathrm{ng} / \mathrm{mL}$.

To the best of our knowledge, the number of cases of upper extremity arterial thromboembolism in patients with COVID-19 is limited in the literature. In these cases, revascularization was achieved with anticoagulant therapy or after thrombectomy. ${ }^{[7,13,17-19]}$ In the present case, although arterial thromboembolectomy was performed twice, revascularization could not be achieved and amputation was required at the forearm level.

The most important advantages of peripheral nerve block, compared to general anesthesia and neuraxial block, are that it has less negative 
respiratory and hemodynamic effects and a shorter recovery time. ${ }^{[20]}$ Therefore, it is a good alternative in severe cardiological and pulmonary diseases or in many high-risk situations that prevent general or neuraxial anesthesia, such as anticoagulant therapy. Since the anesthetist would have direct contact with the patient's airway during intubation and extubation while performing general anesthesia, peripheral nerve block has also the advantage of being a less risky option, particularly in cases of COVID-19. ${ }^{[21]}$ In addition, it has been demonstrated to be useful in preventing phantom pain that may develop later in cases of amputation. ${ }^{[22]}$ Hence, we also preferred peripheral nerve block in our case to avoid possible complications of general anesthesia.

In conclusion, whether patients has comorbide diseases, predispozan factors or not hy percoagulability status can be seen in COVID-19 patients. Although venosus thromboembolisms are frequently seen clinic prensentations arteriel thromboembolisms can be seen too. Care must be taken especially in ICU patients; rapid identification, evaluation and surgical intervation (if needed) are essential for good prognosis.

\section{Declaration of conflicting interests}

The authors declared no conflicts of interest with respect to the authorship and/or publication of this article.

\section{Funding}

The authors received no financial support for the research and/or authorship of this article.

\section{REFERENCES}

1. Huang C, Wang Y, Li X, Ren L, Zhao J, Hu Y, et al. Clinical features of patients infected with 2019 novel coronavirus in Wuhan, China. Lancet 2020;395:497-506.

2. WHO. COVID-19 Dashboard. Geneva: World Health Organization; 2020. Available at: https://covid19.who.int

3. Bhatraju PK, Ghassemieh BJ, Nichols M, Kim R, Jerome KR, Nalla AK, et al. Covid-19 in critically ill patients in the Seattle region - Case Series. N Engl J Med 2020;382:2012-22.

4. Lee SG, Fralick M, Sholzberg M. Coagulopathy associated with COVID-19. CMAJ 2020;192:E583.

5. Klok FA, Kruip MJHA, van der Meer NJM, Arbous MS, Gommers DAMPJ, Kant KM, et al. Incidence of thrombotic complications in critically ill ICU patients with COVID-19. Thromb Res 2020;191:145-7.

6. Lodigiani C, Iapichino G, Carenzo L, Cecconi M, Ferrazzi $\mathrm{P}$, Sebastian $\mathrm{T}$, et al. Venous and arterial thromboembolic complications in COVID-19 patients admitted to an academic hospital in Milan, Italy. Thromb Res 2020;191:9-14.

7. Etkin Y, Conway AM, Silpe J, Qato K, Carroccio A, ManvarSingh $\mathrm{P}$, et al. Acute arterial thromboembolism in patients with COVID-19 in the New York city area. Ann Vasc Surg 2021;70:290-4.

8. Atik OŞ. What are the expectations of an editor from a scientific article? Jt Dis Relat Surg 2020;31:597-8.

9. Gavriilaki E, Brodsky RA. Severe COVID-19 infection and thrombotic microangiopathy: Success does not come easily. Br J Haematol 2020;189:e227-e230.

10. Oxley TJ, Mocco J, Majidi S, Kellner CP, Shoirah H, Singh IP, et al. Large-vessel stroke as a presenting feature of Covid-19 in the young. N Engl J Med 2020;382:e60.

11. Ranucci M, Ballotta A, Di Dedda U, Bayshnikova E, Dei Poli M, Resta M, et al. The procoagulant pattern of patients with COVID-19 acute respiratory distress syndrome. J Thromb Haemost 2020;18:1747-51.

12. Parra-Medina R, Herrera S, Mejia J. Systematic Review of Microthrombi in COVID-19 Autopsies. Acta Haematol 2021;19:1-8

13. Bellosta R, Luzzani L, Natalini G, Pegorer MA, Attisani L, Cossu LG, et al. Acute limb ischemia in patients with COVID-19 pneumonia. J Vasc Surg 2020;72:1864-72.

14. Iba T, Connors JM, Levy JH. The coagulopathy, endotheliopathy, and vasculitis of COVID-19. Inflamm Res 2020;69:1181-9.

15. Ahmed MU, Hanif M, Ali MJ, Haider MA, Kherani D, Memon GM, et al. Neurological manifestations of COVID19 (SARS-CoV-2): A review. Front Neurol 2020;11:518.

16. Abou-Ismail MY, Diamond A, Kapoor S, Arafah Y, Nayak L. The hypercoagulable state in COVID-19: Incidence, pathophysiology, and management. Thromb Res 2020;194:101-15.

17. Ogawa M, Doo FX, Somwaru AS, Roudenko A, Kamath A, Friedman B. Peripheral arterial occlusion due to COVID-19: $\mathrm{CT}$ angiography findings of nine patients. Clin Imaging 2021;73:43-7.

18. Scott BA, Garg K, Johnson W, Al-Ajam M, Patalano P, Rotella V, et al. Upper extremity arterial thromboembolism in a coronavirus patient. A case report. SN Compr Clin Med 2021:1-6.

19. Hanif M, Ali MJ, Haider MA, Naz S, Ahmad Z. Acute upper limb ischemia due to arterial thrombosis in a mild COVID19 patient: A case report. Cureus 2020;12:e10349.

20. Missair A, Gebhard R, Pierre E, Cooper L, Lubarsky D, Frohock J, et al. Surgery under extreme conditions in the aftermath of the 2010 Haiti earthquake: The importance of regional anesthesia. Prehosp Disaster Med 2010;25:487-93.

21. Randelli PS, Compagnoni R. Management of orthopaedic and traumatology patients during the Coronavirus disease (COVID-19) pandemic in northern Italy. Knee Surg Sports Traumatol Arthrosc 2020;28:1683-9.

22. Birbaumer N, Lutzenberger W, Montoya P, Larbig W, Unertl K, Töpfner S, et al. Effects of regional anesthesia on phantom limb pain are mirrored in changes in cortical reorganization. J Neurosci 1997;17:5503-8. 